\title{
Ascitic calprotectin and lactoferrin for detection of spontaneous bacterial peritonitis: a systematic review and meta-analysis
}

\author{
Kishan P. Patel ${ }^{1}$, Parker M. Korbitz ${ }^{2}$,John P. Gallagher ${ }^{1}$, Cynthia Schmidt ${ }^{3}$, Thammasin Ingviya ${ }^{4,5,6}$, \\ Wuttiporn Manatsathit ${ }^{7} \wedge$
}

${ }^{1}$ Department of Internal Medicine, University of Nebraska Medical Center, Omaha, NE, USA; ${ }^{2}$ Department of Internal Medicine, Medical College of Wisconsin, Milwaukee, WI, USA; ${ }^{3}$ McGoogan Library of Medicine, University of Nebraska Medical Center, Omaha, NE, USA; ${ }^{4}$ Department of Family and Preventive Medicine, Faculty of Medicine, Prince of Songkla University, Songkhla, Thailand; ${ }^{5}$ Medical Data Center for Research and Innovation, Faculty of Medicine, Prince of Songkla University, Songkhla, Thailand; ${ }^{6}$ Digital Innovation and Data Analytics, Faculty of Medicine, Prince of Songkla University, Songkhla, Thailand; ${ }^{7}$ Division of Gastroenterology and Hepatology, Department of Internal Medicine, University of Nebraska Medical Center, Omaha, NE, USA

Contributions: (I) Conception and design: T Ingviya, W Manatsathit; (II) Administrative support: C Schmidt, T Ingviya, W Manatsathit; (III) Provision of study materials or patients: KP Patel, PM Korbitz, JP Gallagher, W Manatsathit; (IV) Collection and assembly of data: PM Korbitz, JP Gallagher, W Manatsathit; (V) Data analysis and interpretation: KP Patel, PM Korbitz, W Manatsathit; (VI) Manuscript writing: All authors; (VII) Final approval of manuscript: All authors.

Correspondence to: Wuttiporn Manatsathit, MD. 982000 Nebraska Medical Center, Omaha, NE 68198, USA. Email: shane.manatsathit@unmc.edu.

\begin{abstract}
Background: Spontaneous bacterial peritonitis (SBP) is a common bacterial infection in cirrhotic patients associated with a high mortality rate. Prompt diagnosis and early antibiotic administration are crucial in minimizing adverse outcomes. Although detection of $\geq 250$ polymorphonuclear leukocytes (PMN) in ascitic fluid is the current gold standard to diagnose SBP, consideration for rapid detection with biomarkers is warranted.

Methods: A literature search for studies evaluating ascitic calprotectin and lactoferrin for detection of SBP was performed using PubMed, Embase, Scopus, Google Scholar, Cochrane library, and Clinical Trial Registries. Summary sensitivity, specificity, log diagnostic odds ratio (LDOR), and area under the summary receiver operating curve (AUC) were calculated.

Results: In total, 12 and 13 studies evaluated ascitic calprotectin and lactoferrin, respectively, for detection of SBP. Summary sensitivity, specificity, and LDOR for calprotectin were 0.942 (95\% CI, 0.916, 0.967), 0.860 (95\% CI, 0.799, 0.935), and 4.250 (95\% CI, 3.504, 4.990), respectively. AUC for calprotectin was 0.91. Summary sensitivity, specificity, and LDOR for lactoferrin were 0.954 (95\% CI, 0.930, 0.979), 0.890 (95\% CI, 0.836, 0.945), and 4.630 (95\% CI, 3.800, 5.452), respectively. AUC for lactoferrin was 0.958.

Conclusions: The overall performance of ascitic calprotectin and lactoferrin was substantial, potentially serving as a screening tool or an alternative to manual cell count. However, a variety of manufacturers, cut-off values, and significant heterogeneity between studies should be noted. Point-of-care testing for calprotectin and lactoferrin may resolve disadvantages associated with the current methods. Future studies on this topic are, therefore, needed.
\end{abstract}

Keywords: Lactoferrin; calprotectin; ascites; spontaneous bacterial peritonitis (SBP); cirrhosis

Received: 26 October 2020; Accepted: 26 February 2021; Published: 25 October 2022.

doi: $10.21037 /$ tgh-20-323

View this article at: http://dx.doi.org/10.21037/tgh-20-323

^ ORCID: Wuttiporn Manatsathit, 0000-0003-4406-1588; Kishan P. Patel, 0000-0002-8971-3482. 


\section{Introduction}

A diagnosis of spontaneous bacterial peritonitis (SBP) is essential for cirrhotic patients considering significant associated morbidity and mortality. SBP is the most common bacterial infection among cirrhotic patients accounting for approximately $10-30 \%$ of all bacterial infections in hospitalized cirrhotic patients (1). Most importantly, patients with SBP are at risk of acute kidney injury and acute on chronic liver failure, which significantly increases risk of mortality (2). With a rise in multi-drug resistant organisms, the management of SBP more heavily relies on the administration of appropriate empiric antibiotic therapies. Piano et al. investigated infections in patient with cirrhosis via an intercontinental study, noting that SBP was the most common bacterial infection, with $27 \%$ of cases, followed by urinary tract infections $(22 \%)$ and pneumonia (19\%). Additionally, there was a higher prevalence of SBP detected in American and European centers compared to Asian centers (3). The hospital mortality of SBP was previously estimated to be between $10-50 \%$ for first episodes, and 31-93\% for subsequent episodes; with recent studies suggesting a one-month mortalities greater than $20 \%$. Furthermore, third-generation cephalosporins are still effective for community-acquired SBP but were thought to be as low as $40 \%$ effective in nosocomial infections (4). A study by Kim et al. also demonstrated a 2.7 -fold increase in mortality when a diagnosis is delayed (5). For these reasons, prompt diagnosis and early antibiotic treatment are crucial in successful treatment and minimizing these adverse outcomes.

Currently, the diagnosis of SBP is established when polymorphonuclear $(\mathrm{PMN})$ counts are $\geq 250$ cells $/ \mathrm{mm}^{3}$ in the ascitic fluid $(1,2,6)$. The laboratory process is generally performed by manual cell count using an optical microscope. However, several steps during this process are subject to deficiency. Lysis of PMNs during transport can occur, leading to false-negative results. Additionally, the manual cell count is subject to human error, and laboratory processing time can take several hours to result (7). Although automated techniques have become increasingly popular over the manual cell count, the availability of automated cell count remains limited, especially in a rural area or small facilities (8). As a delay in diagnosing SBP significantly contributes to a worse prognosis, efficient alternative diagnostic methods are crucial.

In an effort to expedite the detection of SBP, biochemical markers of PMNs, such as ascitic calprotectin and lactoferrin, have been studied. Calprotectin is a calcium-binding antimicrobial protein found almost exclusively in neutrophil cytosol, whereas lactoferrin is a glycoprotein found in granules of PMNs (9-11). Studies have suggested the potential for a faster turnaround time and even bedside point of care testing when compared to the manual count; laboratory capacity and hours of operation, including overnight and on weekends, can affect detection and delay antibiotic administration. Though non-specific, biomarkers such as calprotectin act as surrogate markers for neutrophilic turnover in the presence of inflammation. Calprotectin and lactoferrin have been extensively studied in other inflammatory or infectious conditions such as inflammatory bowel disease and urinary tract infection. Similarly, both of these markers can be measured in the ascitic fluid by the enzyme-linked immunosorbent assay (ELISA) method. Notably, calprotectin and lactoferrin are extremely stable and not subject to error from cell lysis $(12,13)$. Early studies have also demonstrated a linear relationship between the level of ascitic calprotectin and lactoferrin and ascitic neutrophil count $(14,15)$. Therefore, detection of calprotectin and lactoferrin in an ascitic fluid may potentially serve as a diagnostic tool for SBP. However, the performance of calprotectin and lactoferrin appeared to vary due to differences in the study population and manufacturers. Hence, we conducted this meta-analysis to examine the performance of ascitic calprotectin and lactoferrin for detection of SBP by following the PRISMA and Cochrane guidelines. We present the following article in accordance with the PRISMA reporting checklist (available at https:// tgh.amegroups.com/article/view/10.21037/tgh-20-323/rc).

\section{Methods}

This meta-analysis was performed in accordance to Cochrane's manual of diagnostic test accuracy as outlined by the preferred reporting items for systematic reviews and meta-analysis of diagnostic test accuracy (PRISMA-DTA) guidelines $(16,17)$. A literature search of PubMed, Embase, Scopus, Google Scholar, Cochrane, ClinicalTrials.gov, and European Clinical Trial Registry was performed through March 2020 by a librarian (C.S.) specialized in a systemic review. Search terms included: (I) SBP; (II) calprotectin; and (III) lactoferrin. The detail regarding search terms is shown in the supplementary document. SBP was defined by a $\mathrm{PMN} \geq 250^{*}$ cells $/ \mathrm{mm}^{3}$ regardless of ascitic fluid culture. Calprotectin and lactoferrin were measured on ascitic fluid. The titles and abstracts obtained through the searching and screening process were reviewed by two independent 
authors (P.M.K. and J.P.G.). Discrepancies were carefully resolved amongst the two independent authors and a senior author (W.M.). The independent authors extracted and compiled data from each study, which consisted of study characteristics and results such as author, year of publication, start and end dates for data collection, country, and type of study design. Study population characteristics include the number of patients, number of paracenteses performed, mean age, number of inpatients, number of outpatients, Child-Pugh score, and criteria for the diagnosis of SBP. Exclusion criteria included secondary causes of other causes of neutrocytic ascites, such as malignancy, other intra-abdominal infection(s), recent abdominal surgeries, or recent exposure to antibiotics. Abstracted data include the prevalence of SBP, method of detection, the cut-off level used, sensitivity, specificity, true positive, false positive, false negative, and true negative. This information was extracted from the study itself or calculated utilizing other information. The primary outcome of the study was the overall performance of ascitic calprotectin and lactoferrin in the detection of SBP as determined by summary sensitivity, specificity, log diagnostic odds ratio (LDOR), and the area under summary receiver operating characteristic (SROC) curves (AUC). The secondary outcomes are summary statistics from the subgroup analyses performed. Quality assessment for each individual study for use in this metaanalysis was performed using QUADAS-2 by the same two independent authors (P.M.K. and J.P.G.). Any discrepancies during the process were again resolved following discussion with the senior author (W.M.).

\section{Statistical analysis}

R version 3.2.4 (R Core team 2013) with Metafor and Mada packages was used for the statistical analysis in this study $(18,19)$. By using Cohen's Kappa coefficient, an interobserver agreement was evaluated. Summary sensitivity, specificity, and LDOR were calculated by bivariate metaanalysis as described by Reitsma (20). The hierarchical summary receiver operating characteristic model was utilized to calculate the summary receiver operating characteristic (SROC) as described by Rutter and Gatsonis (21). AUC was then calculated. Sensitivity analysis was performed by conducting subgroup analyses based on the method of detection, the setting of paracenteses (inpatient), and manufacturers. A P value $<0.05$ was considered statistically significant. Study heterogeneity was evaluated by the $\mathrm{I}^{2}$ statistic. $\mathrm{I}^{2}$ of $0-40 \%, 50-90 \%, 30-60 \%$, and $75-100 \%$ were considered low, moderate, substantial, and considerable (22). Publication biases were assessed by Deeks' funnel plot where a $\mathrm{P}$ value $<0.1$ suggests evidence of a publication bias (23).

\section{Results}

Figure 1 highlights a flow diagram of the screening and study selection process performed for this analysis. Following the removal of duplicate studies, a total of 247 articles were found using the systematic search criteria. Of these, 32 articles were noted to be relevant. Ultimately, 23 studies were included in this meta-analysis, including one abstract and 22 full articles. Specifically, 12 of the 23 studies investigated the performance of calprotectin, and 13 of the 23 studies investigated the performance of lactoferrin. Characteristics of calprotectin and lactoferrin ELISA kit manufacturers used in each study are shown in Table $\mathrm{S} 1$.

\section{Study characteristics}

Table 1 demonstrates the characteristics of each study evaluating calprotectin for the detection of SBP, whereas Table S2 demonstrates abstracted data. Among studies evaluating calprotectin, there were 1,046 patients with a total of 1,191 paracenteses performed. The prevalence of SBP was $51.22 \%$ ranging from $15.25 \%$ to $71.43 \%$. All studies utilized ELISA-based techniques, whereas one study utilized point-of-care testing. Five studies included only inpatient data, whereas only one study included outpatient data exclusively. Six studies in total did not specify the setting in which samples were collected. The cut-off values for ascitic calprotectin range from $0.002 \mu \mathrm{g} / \mathrm{mL}$ to $2.89 \mathrm{ng} / \mathrm{mL}$.

Table 1 also demonstrates the characteristics of each study evaluating lactoferrin for the detection of SBP, whereas Table S3 demonstrates abstracted data. Among studies evaluating lactoferrin, there were 1,291 patients with a total of 1,457 paracenteses performed. The prevalence of SBP was $42.03 \%$ ranging from $10.09 \%$ to $71.43 \%$. Three studies did not report laboratory techniques for the detection of lactoferrin, whereas the remainder used ELISA-based techniques. A total of eight studies included only inpatient data, whereas five studies did not specify the setting in which samples were collected. The cut-off values for ascitic lactoferrin range from 46.1 to $300 \mathrm{ng} / \mathrm{mL}$.

\section{Performance of ascitic calprotectin for detection of SBP}

For ascitic calprotectin, summary sensitivity, specificity, 


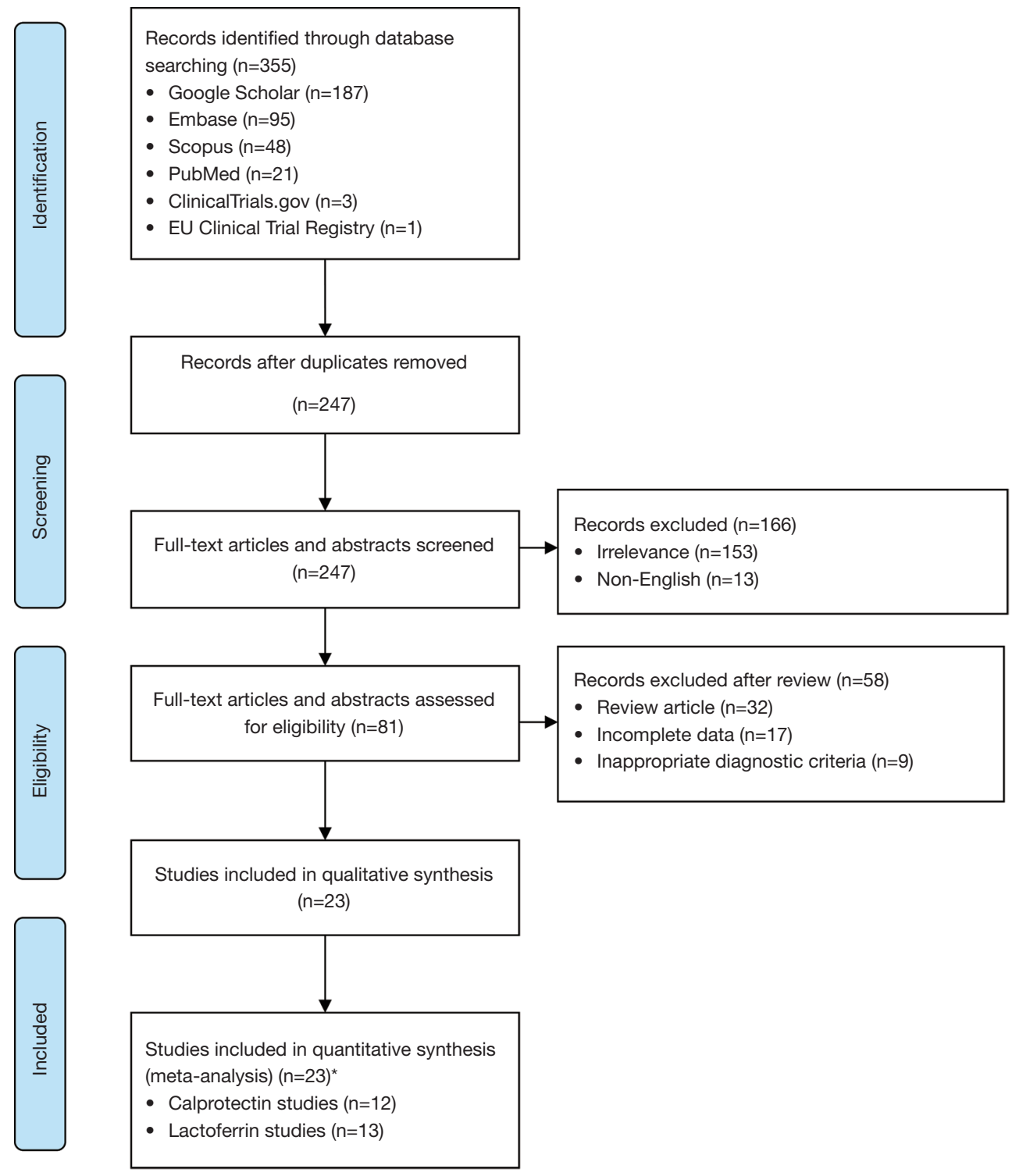

Figure 1 A flowchart demonstrating the study search and selection process for this meta-analysis according to the PRISMA statement. ( ${ }^{*}$ two studies evaluated both ascites calprotectin and lactoferrin for the detection of SBP). SBP, spontaneous bacterial peritonitis.

LDOR were 0.942 (95\% CI, 0.916, 0.967), 0.867 (95\% CI, $0.799,0.935)$, and 4.250 (95\% CI, 3.504, 4.990), respectively (see Table 2). The level of heterogeneity for summary sensitivity, specificity, and LDOR was moderate (43.04\%), considerable $(89.70 \%)$, and low $(12.46 \%)$, respectively. Figure $2 A, 2 B$ demonstrated a graphical representation of the summary sensitivity and specificity of calprotectin. SROC is shown in Figure S1A (AUC =0.91). Subgroup analyses, according to the manufacturers and method of calprotectin detection, were not possible due to an inadequate amount of data. Of the five studies evaluating inpatient solely, the summary sensitivity, specificity, LDOR were 0.957 (95\% CI, 0.922, 0.993), 0.830 (95\% CI, 0.676, 0.984), and 4.360 (95\% CI, 2.774, 5.950) with similar levels of heterogeneity as the overall performance.

\section{Performance of ascitic lactoferrin for detection of SBP}

For ascitic lactoferrin, summary sensitivity, specificity, and LDOR were 0.954 (95\% CI, 0.930, 0.979), 0.890 (95\% CI, 
Table 1 Characteristics of studies evaluating ascitic calprotectin and lactoferrin for detection of SBP

\begin{tabular}{|c|c|c|c|c|c|c|c|c|c|c|c|c|}
\hline Study & Type & $\begin{array}{l}\text { Country/ } \\
\text { Region }\end{array}$ & Study type & Method & Start date & End date & $\begin{array}{c}\text { Mean } \\
\text { age } \\
\text { (years) }\end{array}$ & $\begin{array}{l}\text { Sample } \\
\text { size (n) }\end{array}$ & $\begin{array}{c}\text { Outpatient } \\
\text { vs. } \\
\text { inpatient }\end{array}$ & \multicolumn{3}{|c|}{ Child-Pugh score } \\
\hline $\begin{array}{l}\text { Abdel Rahman } \\
\text { et al. (24) }\end{array}$ & Full paper & Egypt & NR & ELISA & NR & NR & $55 \pm 8$ & 80 & Outpatient & 0 & 16 & 64 \\
\hline Ali et al. (26) & Full paper & Egypt & NR & ELISA & May 2017 & Apr 2018 & $52 \pm 5$ & 72 & Inpatient & 0 & 18 & 54 \\
\hline El-Baz et al. (27) & Full paper & Egypt & Prospective & ELISA & Aug 2016 & Dec 2017 & $53 \pm 8$ & 88 & Inpatient & 0 & 33 & 54 \\
\hline Fernades et al. (9) & Full paper & Portugal & Prospective & POC & NR & NR & $62 \pm 12$ & 88 & NR & 3 & 46 & 39 \\
\hline Makhlouf et al. (31) & Full paper & Egypt & Cross-sectional & ELISA & Apr 2015 & Sep 2015 & 52 & 87 & Inpatient & 0 & 10 & 77 \\
\hline $\begin{array}{l}\text { Mohammed } \\
\text { et al. (32) }\end{array}$ & Full paper & Egypt & Cross-sectional & ELISA & NR & NR & $56 \pm 8$ & 60 & NR & 0 & 33 & 27 \\
\hline Rizk et al. (14) & Full paper & Egypt & Prospective & ELISA & Oct 2012 & Mar 2013 & NR & 124 & NR & 0 & 88 & 36 \\
\hline Weil et al. (33) & Full paper & France & Prospective & ELISA & May 2016 & May 2017 & $62 \pm 11$ & 128 & NR & 2 & 42 & 75 \\
\hline \multicolumn{13}{|l|}{ Lactoferrin } \\
\hline Abuelfadi et al. (34) & Full paper & Egypt & Cross-sectional & ELISA & July 2016 & Feb 2017 & $64 \pm 8$ & 150 & NR & NR & NR & NR \\
\hline Kumar et al. (38) & Abstract & NR & Prospective & NR & NR & NR & NR & 115 & NR & 0 & 94 & 21 \\
\hline Lee et al. (39) & Full paper & $\begin{array}{l}\text { South } \\
\text { Korea }\end{array}$ & Prospective & ELISA & Dec 2008 & Dec 2011 & 54.5 & 102 & NR & NR & NR & NR \\
\hline Liang et al. (40) & Full paper & China & NR & NR & May 2011 & Dec 2011 & NR & 66 & Inpatient & NR & NR & NR \\
\hline Makhlouf et al. (31) & Full paper & Egypt & Cross-sectional & ELISA & Apr 2015 & Sep 2015 & 52 & 87 & Inpatient & 0 & 10 & 77 \\
\hline $\begin{array}{l}\text { Mohammad } \\
\text { et al. (41) }\end{array}$ & Full paper & Egypt & NR & ELISA & Dec 2013 & Feb 2014 & NR & 84 & Inpatient & NR & NR & NR \\
\hline Parsi et al. (7) & Full paper & USA & Prospective & ELISA & NR & NR & NR & 148 & NR & NR & NR & NR \\
\hline Salman et al. (42) & Full paper & Egypt & NR & NR & Mar 2010 & Mar 2010 & NR & 51 & Inpatient & NR & NR & NR \\
\hline
\end{tabular}

ELISA, enzyme-linked immunosorbent assay; NR, not reported; PMN, polymorphonuclear leukocytes; SBP, spontaneous bacterial peritonitis. 
Table 2 The results of the meta-analysis of studies evaluating ascitic calprotectin and lactoferrin for the detection of SBP

\begin{tabular}{|c|c|c|c|c|c|c|c|c|}
\hline & $\begin{array}{l}\text { Number of } \\
\text { studies (n) }\end{array}$ & $\begin{array}{l}\text { Sensitivity } \\
(95 \% \mathrm{Cl})\end{array}$ & $\begin{array}{l}1^{2} \\
(\%)\end{array}$ & $\begin{array}{l}\text { Specificity } \\
(95 \% \text { Cl) }\end{array}$ & $\begin{array}{c}1^{2} \\
(\%)\end{array}$ & $\begin{array}{c}\text { LDOR } \\
(95 \% \mathrm{Cl})\end{array}$ & $\begin{array}{c}\mathrm{I}^{2} \\
(\%)\end{array}$ & AUC \\
\hline \multicolumn{9}{|l|}{ Calprotectin } \\
\hline Study characteristics: inpatient & 5 & $0.957(0.922,0.993)$ & 40.52 & $0.830(0.676,0.984)$ & 94.38 & $4.360(2.774,5.950)$ & 28.77 & 0.949 \\
\hline \multicolumn{9}{|l|}{ Lactoferrin } \\
\hline Study characteristics: inpatient & 8 & $0.952(0.920,0.983)$ & 54.59 & $0.899(0.830,0.968)$ & 85.52 & $4.623(3.579,5.668)$ & 2.18 & 0.957 \\
\hline
\end{tabular}

$\mathrm{I}^{2}$, study heterogeneity; AUC, area under the summary receiver operating curve; $\mathrm{Cl}$, confidence interval; ELISA, enzyme-linked immunosorbent assay; LDOR, log diagnostic odds ratio; SBP, spontaneous bacterial peritonitis.

A

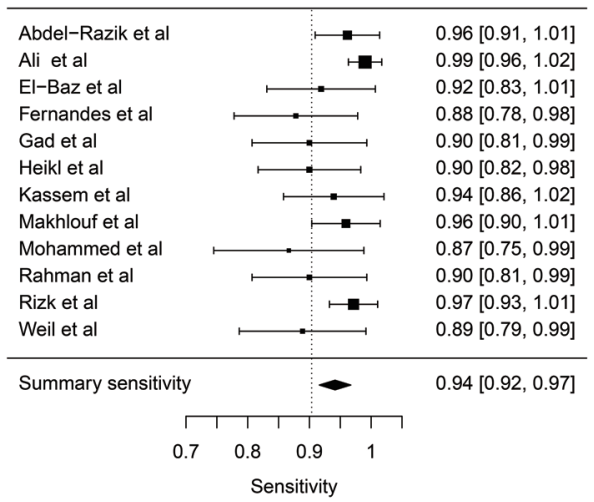

C

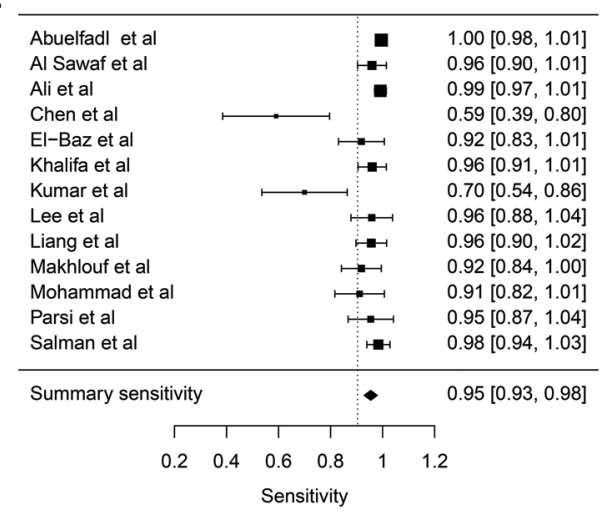

B

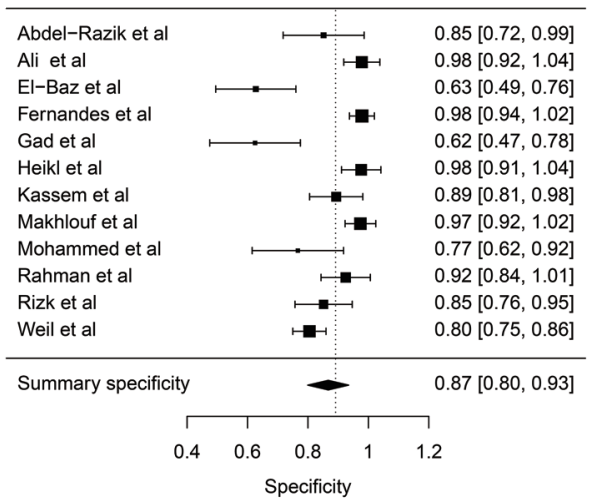

D

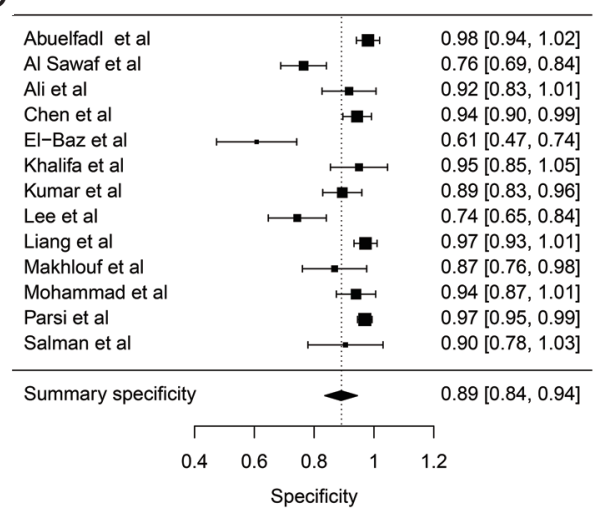

Figure 2 Forest plots demonstrating individual and summary sensitivity and specificity of each study evaluating ascitic calprotectin and lactoferrin for the detection of SBP: sensitivity of calprotectin (A), specificity of calprotectin (B), sensitivity of lactoferrin (C), and specificity of lactoferrin (D). SBP, spontaneous bacterial peritonitis.

$0.836,0.945)$, and 4.630 (95\% CI, 3.800, 5.452), respectively (see Table 2). The level of heterogeneity for summary sensitivity, specificity, and LDOR were substantial (65.51\%), considerable $(91.04 \%)$, and low $(15.24 \%)$, respectively.
Figure $2 C, 2 D$ demonstrated a graphical representation of the summary sensitivity and specificity of lactoferrin. SROC is shown in Figure S1B (AUC $=0.958$ ). Subgroup analysis, according to manufacturers and method of lactoferrin 
detection, was not possible due to an inadequate amount of information. Of the eight studies evaluating inpatient solely, the summary sensitivity, specificity, LDOR were 0.952 (95\% CI, 0.920, 0.983), 0.899 (95\% CI, 0.830, 0.968), and 4.623 (95\% CI, 3.579, 5.668) with similar levels of heterogeneity as the overall performance.

\section{Quality assessment and publication bias}

During the screening process performed, our independent authors demonstrated a high degree of agreement, as supported by Cohen's kappa coefficient of 0.95. Simplified QUADAS-2 for studies investigating ascitic fluid calprotectin and lactoferrin are shown in Table 3, whereas an in-depth QUADAS-2 is shown as Table S4. In general, the overall concern for a patient selection bias, applicability of findings, conduct, or interpretation of the index test was found to be low. Utilizing Deeks' funnel plot, no publication bias was found among studies evaluating calprotectin and lactoferrin for the detection of SBP $(\mathrm{P}=0.325$ and 0.956 , respectively) (Figures 3,4).

\section{Discussion}

Our meta-analysis demonstrated a considerable sensitivity and good specificity for both ascitic calprotectin and lactoferrin for the detection of SBP. Although the performance of ascitic lactoferrin appeared to be slightly better than calprotectin, this was not statistically significant. SBP was previously diagnosed by the presence of $\geq 250$ $\mathrm{PMNs}$ in an ascitic fluid along with positive ascitic fluid culture; however, patients with culture-negative neutrocytic ascites carried similar morbidity and mortality, and, therefore, PMNs count became the standard for diagnosis of SBP regardless of the culture (43). Currently, the manual cell count remains the gold standard for obtaining a PMN count; however, this generally takes several hours to result. Additionally, the manual cell count cannot be performed in various settings, such as rural sites, small medical facilities, and developing countries.

In the past decade, several inflammatory markers have been shown to be associated with SBP, including tumor necrosis factor- $\alpha$, interleukin-6, C-reactive protein, procalcitonin, leukocyte esterase, calprotectin, and lactoferrin $(7,9,10,44,45)$. The stability of biochemical markers is thought to exceed that of PMNs; for example, lactoferrin was noted to be more resistant and stable when left at room temperature for several hours (7). Leukocyte esterase testing, in the form of reagent test strips, has also drawn interest as the results could be interpreted at the bedside and potentially allow for more rapid detection of SBP without the need for laboratory testing. Calprotectin and lactoferrin should be used with caution in patients with secondary causes of peritonitis, such as inflammation secondary to malignancy, other infections, which may result in false positives. Likewise, an impaired immune response or conditions such as granulocytopenia may potentially result in false negative results.

In the previous studies, the performance of ascitic calprotectin and lactoferrin in the detection of SBP appeared promising but has often varied, which may be in part due to the variable cut-off values or prevalence of SBP noted in each study. For example, studies by Ali et al. and Heikl et al. suggested that the prevalence of SBP in their findings were $69.44 \%$ and $71.43 \%$, respectively, but both demonstrated the specificity of $100 \%$ despite varying cutoff values ( 0.372 versus $0.783 \mu \mathrm{g} / \mathrm{mL})$. In addition, AbdelRazik et al. had a comparable prevalence and cut-off value to Ali et al. (65.82\% and cut-off $0.445 \mathrm{ug} / \mathrm{mL}$ versus $69.44 \%$ and cut-off $0.372 \mu \mathrm{g} / \mathrm{mL})$; however, their specificities were inconsistent $(85.2 \%$ versus $100 \%)$.

In this meta-analysis, both ascitic calprotectin and lactoferrin had an excellent overall performance as reflected by AUC of 0.91 and 0.958 , respectively. Our data suggested that both ascitic calprotectin and lactoferrin could potentially be utilized as a screening to SBP given a notable sensitivity (0.942 and 0.954 , respectively). The advantages of calprotectin and lactoferrin include a more rapid turnaround time and less human error as compared with manual cell count. In theory, these methods can minimize delays in the detection of SBP and decrease utilization of unnecessary empirical antibiotics, ultimately decreasing patients' risk for Clostridium Difficile infection, multidrug resistance bacteria, and various other side effects of antibiotic use.

Despite several advantages and potential clinical use of calprotectin and lactoferrin, these markers also are subject to disadvantages. The main disadvantage is the lack of standardization in regard to cut-off values, processing techniques, and ELISA kit manufacturers. For example, the cut-off values in studies utilizing ELISA kit for Immunodiagnostik were $0.270,0.372$, and $0.445 \mathrm{ug} / \mathrm{mL}$, whereas cut-off values for Sunred-bio kits were $2.89 \mathrm{ng} / \mathrm{mL}$, $0.950 \mu \mathrm{g} / \mathrm{mL}$, and $0.620 \mu \mathrm{g} / \mathrm{mL}$. We hypothesized that these could be the explanation to a higher level of heterogeneity of specificity for both ascitic calprotectin and lactoferrin; 
Table 3 Simplified QUADAS form of studies evaluating ascitic calprotectin and lactoferrin for the detection of SBP

\begin{tabular}{|c|c|c|c|c|c|c|c|}
\hline \multirow[b]{2}{*}{ Study } & \multicolumn{2}{|c|}{ Patient selection } & \multicolumn{2}{|c|}{ Index test } & \multicolumn{2}{|c|}{ Reference standard } & \multirow{2}{*}{$\begin{array}{c}\text { Flow and } \\
\text { timing } \\
\text { Could the } \\
\text { patient } \\
\text { flow have } \\
\text { introduced } \\
\text { bias? }\end{array}$} \\
\hline & $\begin{array}{l}\text { Could the } \\
\text { selection } \\
\text { of patients } \\
\text { have } \\
\text { introduced } \\
\text { bias? }\end{array}$ & $\begin{array}{l}\text { Is there concern } \\
\text { the included } \\
\text { patients do } \\
\text { not match } \\
\text { the review } \\
\text { question? }\end{array}$ & $\begin{array}{c}\text { Could the } \\
\text { conduct or } \\
\text { interpretation } \\
\text { of the index test } \\
\text { have introduced } \\
\text { bias? }\end{array}$ & $\begin{array}{c}\text { Is there } \\
\text { concern that } \\
\text { the index test, } \\
\text { its conduct, or } \\
\text { interpretation } \\
\text { differ from } \\
\text { the review } \\
\text { question? }\end{array}$ & $\begin{array}{l}\text { Could the } \\
\text { reference } \\
\text { standard, its } \\
\text { conduct, or its, } \\
\text { interpretation } \\
\text { have introduced } \\
\text { bias? }\end{array}$ & $\begin{array}{l}\text { Is there concern } \\
\text { the target } \\
\text { condition as } \\
\text { defined by } \\
\text { the reference } \\
\text { standard does } \\
\text { not match the } \\
\text { review question? }\end{array}$ & \\
\hline \multicolumn{8}{|l|}{ Calprotectin } \\
\hline Abdel Rahman et al. (24) & Low & Low & Low & Low & Low & Low & Low \\
\hline Abdel-Razik et al. (25) & Low & Low & Low & Low & Low & Low & Low \\
\hline Fernades et al. (9) & Low & Low & Low & Low & Low & Low & Low \\
\hline Gad et al. (28) & High & Low & Low & Low & Low & Low & Low \\
\hline Heikl et al. (29) & High & Low & Low & Low & Low & Low & Low \\
\hline Kassem et al. (30) & High & Low & Low & Low & Low & Low & Low \\
\hline Makhlouf et al. (31) & Low & Low & Low & Low & Low & Low & Low \\
\hline Mohammed et al. (32) & High & Low & Low & Low & Low & Low & Low \\
\hline Rizk et al. (14) & Low & Low & Low & Low & Low & Low & Low \\
\hline Chen et al. (37) & Low & Low & Low & Low & Low & Low & Low \\
\hline El-Baz et al. (27) & High & Low & Low & Low & Low & Low & Low \\
\hline Khalifa et al. (15) & High & Low & Low & Low & Low & Low & Low \\
\hline Kumar et al. (38) & Low & Low & Low & Low & Low & Low & Low \\
\hline Lee et al. (39) & Low & Low & Low & Low & Low & Low & Low \\
\hline Liang et al. (40) & High & Low & Low & Low & Low & Low & Low \\
\hline Makhlouf et al. (31) & Low & Low & Low & Low & Low & Low & Low \\
\hline Mohammad et al. (41) & Low & Low & Low & Low & Low & Low & Low \\
\hline Parsi et al. (7) & Low & Low & Low & Low & Low & Low & Low \\
\hline Salman et al. (42) & Low & Low & Low & Low & Low & Low & Low \\
\hline
\end{tabular}

QUADAS, quality assessment of diagnostic accuracy studies; SBP, spontaneous bacterial peritonitis. 


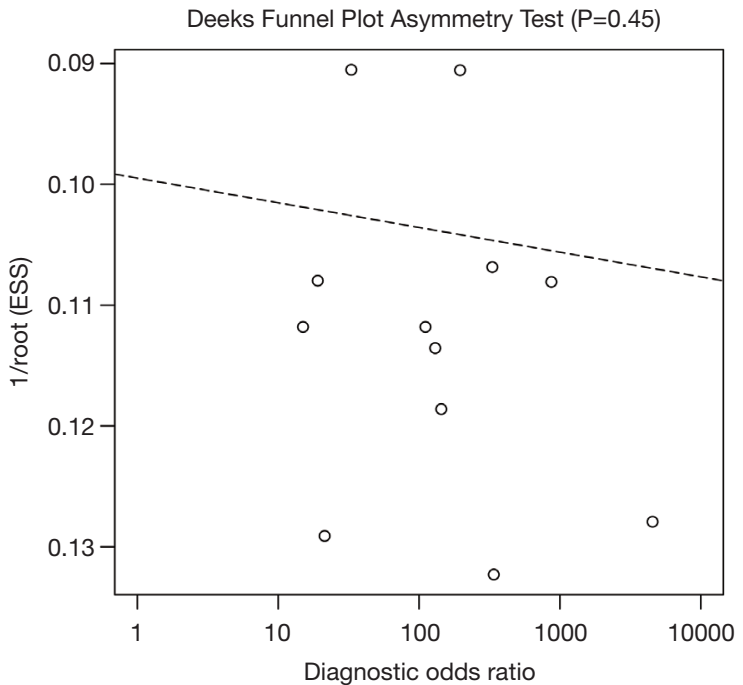

Figure 3 Deeks' funnel plot of studies evaluating ascitic calprotectin for the detection of SBP. ESS, effective sample size; SBP, spontaneous bacterial peritonitis.

however, we were unable to confirm this due to inadequate studies for the subgroup analyses.

Recently, point-of-care-testing (POCT) for calprotectin and lactoferrin has been developed. These methods have a very rapid turnaround time, typically within an hour, and often have more consistent processing techniques due to dedicated analyzers. Therefore, POCT testing could potentially resolve all of the disadvantages present in the current ELISA methods, resulting in a standardized approach with consistent cut-off values. A few studies evaluating POCT detection of calprotectin and lactoferrin have recently been published, however, the number of studies were not adequate for inclusion in this metaanalysis. Nevertheless, these new methods remain expensive and are still under investigation. Our findings, therefore, emphasize the need for future studies to evaluate these POCT methods to diagnose SBP.

Despite a notable performance of calprotectin and lactoferrin, as seen in this study, several limitations were evident and should be considered. A major limitation includes the wide range of cut-off values used in each study; the cut-off values for both calprotectin and lactoferrin varied widely despite being further classified by subgroups. This is most likely attributable to differences in laboratory techniques and ELISA kit manufacturers. Though limited in this analysis, studies utilizing the same ELISA

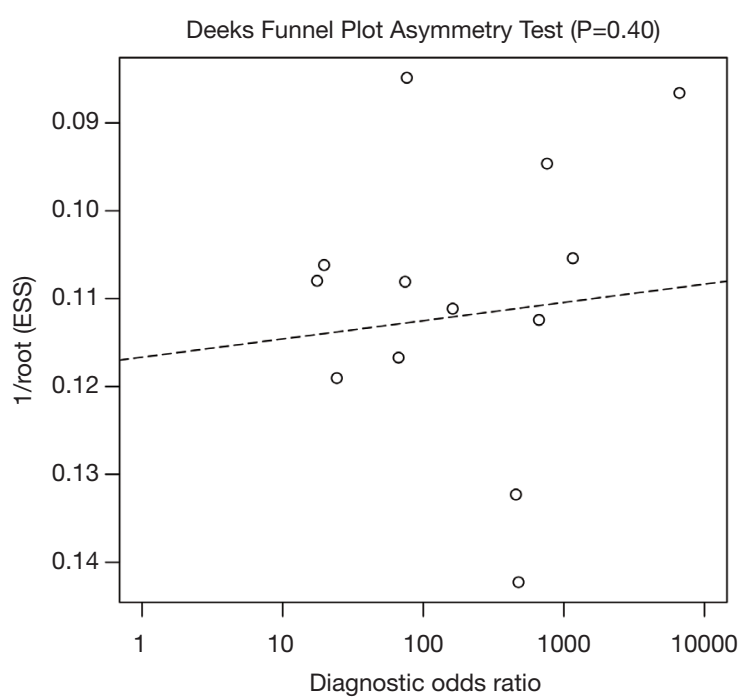

Figure 4 Deeks' funnel plot of studies evaluating ascitic lactoferrin for the detection of SBP. ESS, effective sample size; SBP, spontaneous bacterial peritonitis.

manufacturers supported the notion of varying cut-off values. Again, this emphasizes the need for standardization among ELISA-based methods for detection of calprotectin and lactoferrin. It is notable that a majority of the studies included in this meta-analysis performed paracenteses in the inpatient setting. Some studies also demonstrated a very high incidence of SBP. Lastly, the corresponding values/stages of heterogeneity for summary sensitivity and specificity of calprotectin studies were $43.04 \%$ (moderate), $89.70 \%$ (considerable) whereas the corresponding values/ stages of heterogeneity for summary sensitivity and specificity of lactoferrin were $65.51 \%$ (substantial), $91.04 \%$ (considerable). Therefore, readers and clinicians alike, should take these factors into consideration during the interpretation of this data.

In summary, our data demonstrated notable overall performance of ascitic calprotectin and lactoferrin for the detection of SBP. Calprotectin and lactoferrin have the potential to become a rapid screening tool. The clinical significance of such methods lies in the fact that rapid and reliable diagnostic tests for SBP can serve to decrease time to diagnosis and initiation of antibiotic therapy. Standardization and agreement on cut-off values are necessary. Future studies evaluating POCT for ascitic calprotectin and lactoferrin are crucial and could be promising. 


\section{Acknowledgments}

Funding: None.

\section{Footnote}

Reporting Checklist: The authors have completed the PRISMA reporting checklist. Available at https://tgh. amegroups.com/article/view/10.21037/tgh-20-323/rc

Conflicts of Interest: All authors have completed the ICMJE uniform disclosure form (available at https://tgh.amegroups. com/article/view/10.21037/tgh-20-323/coif). The authors have no conflicts of interest to declare.

Ethical Statement: The authors are accountable for all aspects of the work in ensuring that questions related to the accuracy or integrity of any part of the work are appropriately investigated and resolved.

Open Access Statement: This is an Open Access article distributed in accordance with the Creative Commons Attribution-NonCommercial-NoDerivs 4.0 International License (CC BY-NC-ND 4.0), which permits the noncommercial replication and distribution of the article with the strict proviso that no changes or edits are made and the original work is properly cited (including links to both the formal publication through the relevant DOI and the license). See: https://creativecommons.org/licenses/by-nc-nd/4.0/.

\section{References}

1. Song DS. Spontaneous Bacterial Peritonitis. Korean J Gastroenterol 2018;72:56-63

2. Marciano S, Díaz JM, Dirchwolf M, et al. Spontaneous bacterial peritonitis in patients with cirrhosis: incidence, outcomes, and treatment strategies. Hepat Med 2019;11:13-22.

3. Piano S, Singh V, Caraceni P, et al. Epidemiology and Effects of Bacterial Infections in Patients With Cirrhosis Worldwide. Gastroenterology 2019;156:1368-1380.e10.

4. Shizuma T. Spontaneous bacterial and fungal peritonitis in patients with liver cirrhosis: A literature review. World J Hepatol 2018;10:254-66.

5. Kim JJ, Tsukamoto MM, Mathur AK, et al. Delayed paracentesis is associated with increased in-hospital mortality in patients with spontaneous bacterial peritonitis. Am J Gastroenterol 2014;109:1436-42.
6. Ekpanyapong S, Reddy KR. Infections in Cirrhosis. Curr Treat Options Gastroenterol 2019;17:254-70.

7. Parsi MA, Saadeh SN, Zein NN, et al. Ascitic Fluid Lactoferrin for Diagnosis of Spontaneous Bacterial Peritonitis. Gastroenterology 2008;135:803-7.

8. Riggio O, Angeloni S, Parente A, et al. Accuracy of the automated cell counters for management of spontaneous bacterial peritonitis. World J Gastroenterol 2008;14:5689-94.

9. Fernandes SR, Santos P, Fatela N, et al. Ascitic Calprotectin is a Novel and Accurate Marker for Spontaneous Bacterial Peritonitis. J Clin Lab Anal 2016;30:1139-45.

10. Burri E, Schulte F, Muser J, et al. Measurement of calprotectin in ascitic fluid to identify elevated polymorphonuclear cell count. World J Gastroenterol 2013;19:2028-36.

11. Riggio $\mathrm{O}$ and Angeloni $\mathrm{S}$. Ascitic fluid analysis for diagnosis and monitoring of spontaneous bacterial peritonitis. World J Gastroenterol 2009;15:3845-50

12. Poullis A, Foster R, Mendall MA, et al. Emerging role of calprotectin in gastroenterology. J Gastroenterol Hepatol 2003;18:756-62.

13. Kayazawa M, Saitoh O, Kojima K, et al. Lactoferrin in whole gut lavage fluid as a marker for disease activity in inflammatory bowel disease: comparison with other neutrophil-derived proteins. Am J Gastroenterol 2002;97:360-9.

14. Rizk E, Elzehery R, Zakaria S, et al. Ascitic fluid calprotectin and serum C-reactive protein as diagnostic markers for spontaneous bacterial peritonitis. AfroEgyptian Journal of Infectious and Endemic Diseases 2014;4:117-25.

15. Khalifa NA, Abdel-Azzez HA, Hassaneen AM, et al. Ascitic Fluid Lactoferrin as a Diagnostic Marker for Spontaneous Bacterial Peritonitis. Afro-Egyptian Journal of Infectious and Endemic Diseases 2013;3:49-55.

16. Higgins JP, Green S. Cochrane handbook for systematic reviews of interventions: John Wiley \& Sons; 2011.

17. Moher D, Liberati A, Tetzlaff J, et al. Preferred reporting items for systematic reviews and meta-analyses: the PRISMA statement. Ann Int Med 2009;151:264-9.

18. Viechtbauer W. Conducting meta-analyses in $\mathrm{R}$ with the metafor package. J Stat Softw 2010;36:1-48.

19. Doebler P, Holling H. Meta-analysis of diagnostic accuracy with mada. R Packag 2015;1:15.

20. Reitsma JB, Glas AS, Rutjes AW et al. Bivariate analysis of sensitivity and specificity produces informative summary measures in diagnostic reviews. J Clin Epidemiol 
2005;58:982-90.

21. Rutter CM, Gatsonis CA. A hierarchical regression approach to meta-analysis of diagnostic test accuracy evaluations. Stat Med 2001;20:2865-84.

22. Deeks JJ, Higgins JPT, Altman DG. Chapter 10: Analysing data and undertaking meta-analyses. In: Higgins JPT, Thomas J, Chandler J, et al. editors. Cochrane Handbook for Systematic Reviews of Interventions version 6.1 (updated September 2020). Cochrane 2020.

23. Deeks JJ, Macaskill P, Irwig L. The performance of tests of publication bias and other sample size effects in systematic reviews of diagnostic test accuracy was assessed. J Clin Epidemiol 2005;58:882-93.

24. Abdel Rahman EM, Attia FA, Alsebaey A, et al. Ascitic calprotectin as a useful marker in the diagnosis of spontaneous bacterial peritonitis in adults. Egyp Liver J 2020;10:14.

25. Abdel-Razik A, Mousa N, Elhammady D, et al. Ascitic Fluid Calprotectin and Serum Procalcitonin as Accurate Diagnostic Markers for Spontaneous Bacterial Peritonitis. Gut liver 2016;10:624-31.

26. Ali ST, Mohamed N. The value of ascitic fluid calprotectin and calprotectin-to-albumin ratio in the diagnosis and prognosis of spontaneous bacterial peritonitis. The Scientific Journal of Al-Azhar Medical Faculty, Girls 2019;3:527.

27. El-Baz T. Ascitic Fluid Markers Hepcidin, Calprotectin, and Lactoferrin in Early Diagnosis and Follow-up of Spontaneous Bacterial Peritonitis. Med J Cairo Univ 2018;86:3543-9.

28. Gad MA, El-Shewi ME, Sabry J, et al. Role of Calprotectin in Diagnosis of Spontaneous Bacterial Peritonitis in Cirrhotic Patients with Ascites. Afro-Egyptian Journal of Infectious and Endemic Diseases 2015;5:226-34.

29. Heikl AA, El-Nokeety MM, Roshdy E, et al. Ascitic calprotectin as a diagnostic marker for spontaneous bacterial peritonitis in hepatitis $\mathrm{C}$ virus cirrhotic Egyptian patients. Egypt J Intern Med 2018;30:1.

30. Kassem A, Shabana HAS, Aboelenin MM, et al. Comparative study of ascitic fluid and serum levels of calprotectin, procalcitonin and endocan in patients with liver cirrhosis for early diagnosis and prediction of spontaneous bacterial peritonitis. Al-Azhar Medical Journal 2018;47:257-70.

31. Makhlouf NA, Morsy KH, Mahmoud AA, et al. Diagnostic value of ascitic fluid lactoferrin, calprotectin, and calprotectin to albumin ratio in spontaneous bacterial peritonitis. International Journal of Current Microbiology and Applied Sciences 2018;7:2618-31.

32. Mohammed M, Ibrahim W, Salama MM, et al. The ratio of calprotectin to total protein as a diagnostic marker for spontaneous bacterial peritonitis in patients with liver cirrhosis and ascites. Egyptian Journal of Hematology and Bone Marrow Transplantation 2019;6:1-10.

33. Weil D, Heurgue-Berlot A, Monnet E, et al. Accuracy of calprotectin using the Quantum Blue Reader for the diagnosis of spontaneous bacterial peritonitis in liver cirrhosis. Hepatol Res 2019;49:72-81.

34. Abuelfadl S, Heikl A, El-Nokeety MM, et al. Does ascitic fluid lactoferrin has a role in the diagnosis and follow up of spontaneous bacterial peritonitis in hepatitis $\mathrm{C}$ virus cirrhotic patients. Kasr Al Ainy Medical Journal 2018;24:53.

35. Al Sawaf Y, Kassem GK, Taha A, et al. Towards reliable and rapid bedside diagnosis of spontaneous bacterial peritonitis in cirrhotic patients: Multi center study. Hepatol Intern 2013;7:S750.

36. Ali FM, Shehata IH, Abd Elsalam AE, et al. Diagnostic value of lactoferrin ascitic fluid levels in spontaneous bacterial peritonitis. Egyptian Liver Journal 2013;3:54-61.

37. Chen TH, Chiou HL, Tsai MC, et al. Ascitic Fluid Lactoferrin and Proinflammatory Cytokines (TNF- $\alpha$ and IL-6) for the Diagnosis of Spontaneous Bacterial Peritonitis. Chung Shan Medical Journal 2016;27:59-64.

38. Kumar S, Sinha SK, Prasad KK, et al. Comparison of leukocyte esterase reagent strip test and nitrite reagent strip test for rapid diagnosis of spontaneous bacterial peritonitis and correlation with ascitic fluid lactoferrin level. Indian J Gastroenterol 2015;34:A52.

39. Lee SS, Min HJ, Choi JY, et al. Usefulness of ascitic fluid lactoferrin levels in patients with liver cirrhosis. BMC Gastroenterol 2016;16:132.

40. Liang L, Yu L, Daishu Y, et al. Role of lactoferrin and C-Reactive protein in ascites of liver cirrhosis for diagnosis of spontaneous bacterial peritonitis. Chinese Journal of Infection and Chemotherapy 2014;14:219-23.

41. Mohammad AN, Yousef LM, Mohamed HS. Usefulness of Combined Tests for Accurate Diagnosis of Spontaneous Bacterial Peritonitis. Al-Azhar Assiut Medical Journal $2015 ; 13$.

42. Salman TM, Ali MA, Omran GA, et al. Biochemical Markers in Spontaneous Bacterial Peritonitis. Egypt J Biomed Sci 2011;37:17-27.

43. Runyon BA and Hoefs JC. Culture-Negative Neutrocytic Ascites: A Variant of Spontaneous Bacterial Peritonitis. Hepatology 1984;4:1209-11. 
44. Guler K, Vatansever S, Kayacan SM, et al. High sensitivity C-reactive protein in spontaneous bacterial peritonitis with nonneutrocytic ascites. Hepatogastroenterology 2009;56:452-5.

doi: $10.21037 /$ tgh-20-323

Cite this article as: Patel KP, Korbitz PM, Gallagher JP, Schmidt C, Ingviya T, Manatsathit W. Ascitic calprotectin and lactoferrin for detection of spontaneous bacterial peritonitis: a systematic review and meta-analysis. Transl Gastroenterol Hepatol 2022;7:37.
45. Suliman MA, Khalil FM, Alkindi SS, et al. Tumor necrosis factor- $\alpha$ and interleukin- 6 in cirrhotic patients with spontaneous bacterial peritonitis. World J Gastrointest Pathophysiol 2012;3:92-8. 

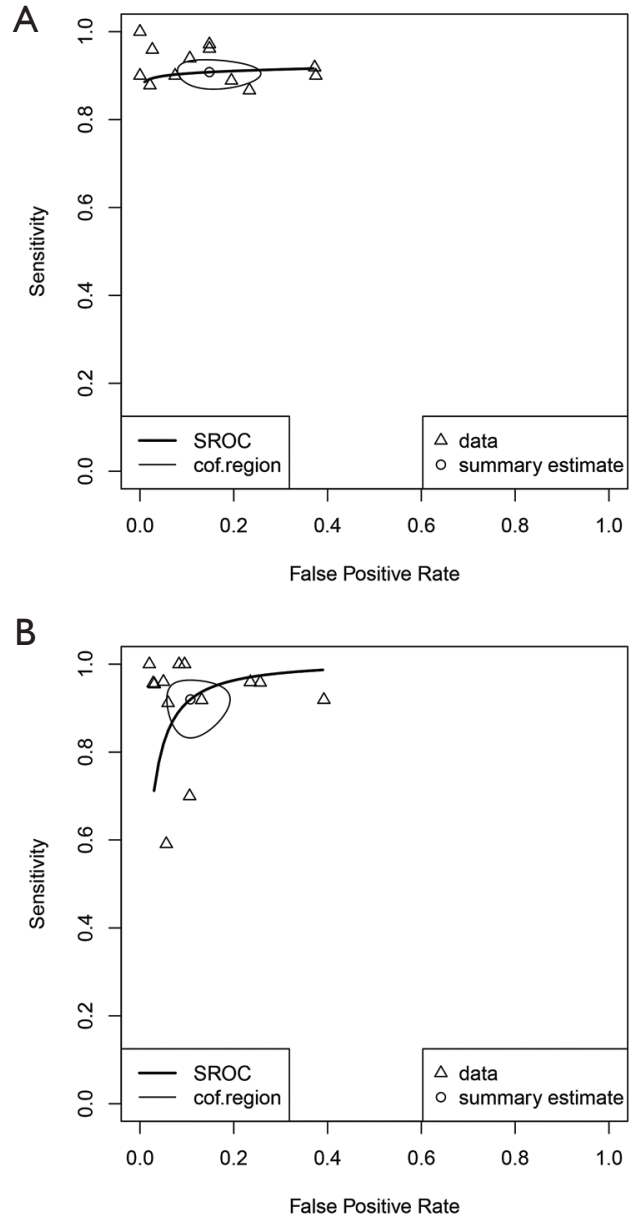

Figure S1 Summary receiver operating characteristic (SROC) curves of studies evaluating ascitic calprotectin (A) and lactoferrin (B) for the detection of SBP. 
Table S1 Characteristics calprotectin and lactoferrin ELISA kit manufacturers in each study

\begin{tabular}{|c|c|c|c|c|}
\hline Author & Name of the tests & Company & City/state & Country \\
\hline Abdel Rahman et al. (24) & NR & Assay Kit Co. & NR & USA \\
\hline Abdel-Razik et al. (25) & NR & Immundiagnostik AG & Bensheim & Germany \\
\hline Ali et al. (26) & NR & Immundiagnostik AG & Bensheim & Germany \\
\hline Fernades et al. (9) & point-of-care High-range-Quantum-Blue & Bühlmann Laboratories AG & Schönenbuch & Switzerland \\
\hline Gad et al. (28) & Sunred Human ELISA kit & Sunred-bio & Shanghai & China \\
\hline Heikl et al. (29) & NR & Epitope Diagnostics & California & USA \\
\hline Kassem et al. (30) & Sunred Human ELISA kit & Sunred-bio & Shanghai & China \\
\hline Rizk et al. (14) & NR & Immundiagnostik AG & Bensheim & Germany \\
\hline Weil et al. (33) & Quantum Blue Calprotectin Ascites & Bühlmann Laboratories AG & Schönenbuch & Switzerland \\
\hline \multicolumn{5}{|l|}{ Lactoferrin } \\
\hline Abuelfadi et al. (34) & Human Lactoferrin ELISA kit & Bethyl Laboratories Inc & Texas & USA \\
\hline Al Sawaf et al. (35) & NR & NR & NR & NR \\
\hline Ali et al. (36) & NR & Bioxytech & Paris & France \\
\hline Chen et al. (37) & NR & NR & NR & NR \\
\hline El-Baz et al. (27) & Assay Max Hu-man Lactoferrin ELISA Kit & AssayPro & Missouri & USA \\
\hline Mohammad et al. (41) & NR & NR & NR & NR \\
\hline Parsi et al. (7) & NR & NR & NR & NR \\
\hline Salman et al. (42) & NR & NR & NR & NR \\
\hline
\end{tabular}

ELISA, enzyme-linked immunosorbent assay; NR, not reported. 
Table S2 Extracted data from studies evaluating ascitic calprotectin for detection of SBP

\begin{tabular}{|c|c|c|c|c|c|c|c|c|c|c|}
\hline Study & $\begin{array}{c}\text { Number of } \\
\text { paracenteses }(n)\end{array}$ & $\begin{array}{l}\text { Prevalence } \\
\text { of SBP (\%) }\end{array}$ & $\begin{array}{l}\text { Cut-off } \\
\text { value }\end{array}$ & Unit & $\begin{array}{l}\text { Sensitivity } \\
(\%)\end{array}$ & $\begin{array}{l}\text { Specificity } \\
(\%)\end{array}$ & $\operatorname{TP}(n)$ & $\mathrm{FP}(\mathrm{n})$ & $\mathrm{FN}(\mathrm{n})$ & $\mathrm{TN}(\mathrm{n})$ \\
\hline Abdel Rahman et al. (24) & 80 & 50 & 0.002 & $\mathrm{ug} / \mathrm{mL}$ & 90 & 92.5 & 36 & 3 & 4 & 37 \\
\hline Ali et al. (26) & 72 & 69.44 & 0.372 & $\mathrm{ug} / \mathrm{mL}$ & 100 & 100 & 50 & 0 & 0 & 22 \\
\hline Gad et al. (28) & 80 & 50 & 2.89 & $\mathrm{ng} / \mathrm{mL}$ & 90 & 62.5 & 36 & 15 & 4 & 25 \\
\hline Heikl et al. (29) & 70 & 71.43 & 0.783 & $\mathrm{ug} / \mathrm{mL}$ & 90 & 100 & 45 & 0 & 5 & 20 \\
\hline Kassem et al. (30) & 90 & 41.25 & 0.950 & $\mathrm{ug} / \mathrm{mL}$ & 95 & 89.2 & 31 & 5 & 2 & 42 \\
\hline Weil et al. (33) & 273 & 15.25 & 0.680 & $\mathrm{ug} / \mathrm{mL}$ & 88.9 & 80.5 & 32 & 39 & 4 & 161 \\
\hline
\end{tabular}

FN, false negative; FP, false positive; $\mathrm{mL}$, milliliter; SBP, spontaneous bacterial peritonitis; TN, true negative; TP, true positive; ug, microgram.

Table S3 Extracted data from studies evaluating ascitic lactoferrin for detection of SBP

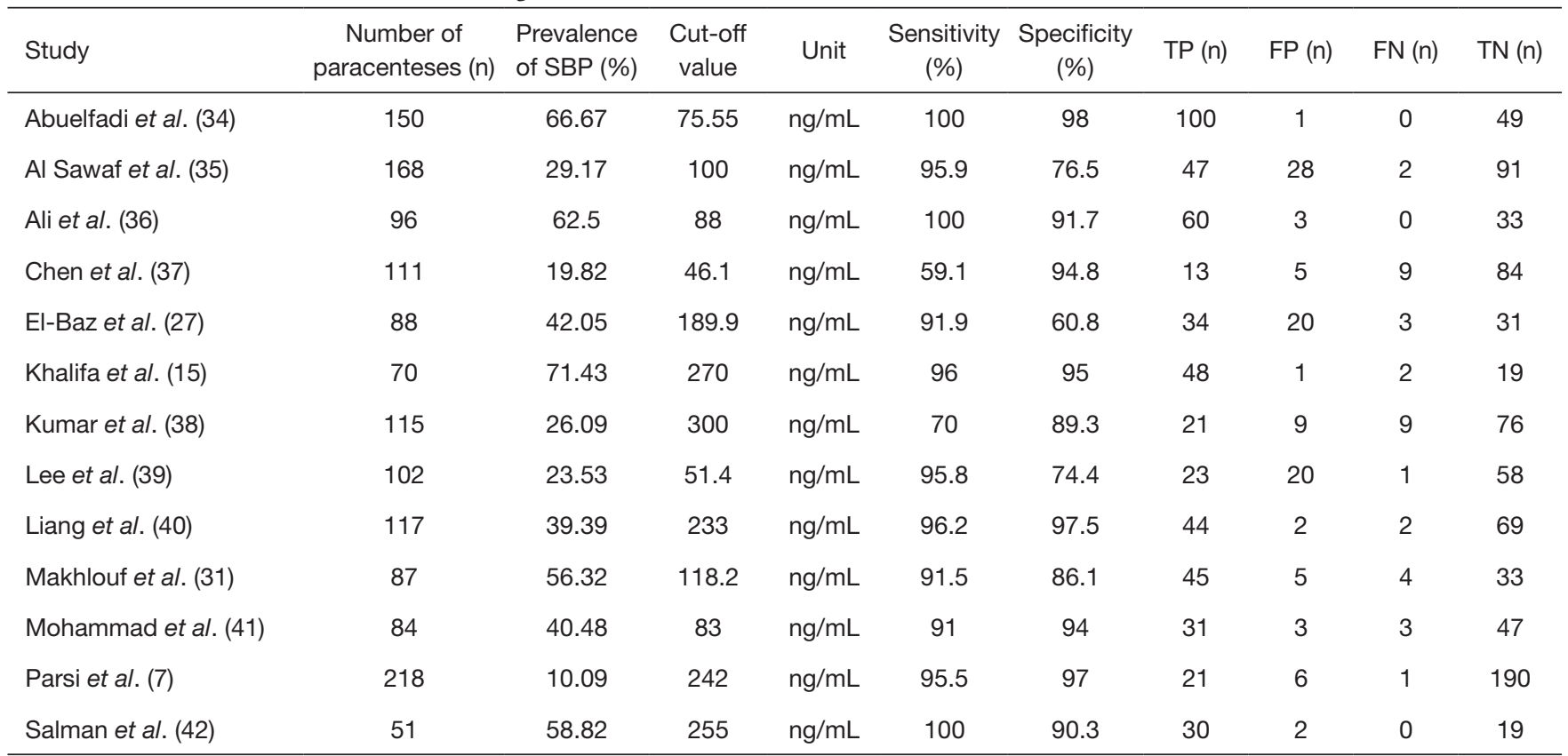

FN, false negative; FP, false positive; $\mathrm{mL}$, milliliter; ng, nanogram; SBP, spontaneous bacterial peritonitis; TN, true negative; TP, true positive. 
Table S4 Detailed QUADAS form of studies evaluating ascitic calprotectin and lactoferrin for the detection of SBP

\begin{tabular}{|c|c|c|c|c|c|c|c|c|c|c|c|c|c|c|c|c|c|}
\hline \multicolumn{5}{|c|}{ Patient selection } & \multicolumn{4}{|c|}{ Index test } & \multicolumn{4}{|c|}{ Reference standard } & \multicolumn{5}{|c|}{ Flow and timing } \\
\hline $\begin{array}{c}\text { Was a } \\
\text { consecutive or } \\
\text { random sample } \\
\text { of patients } \\
\text { enrolled? }\end{array}$ & $\begin{array}{l}\text { Was a case- } \\
\text { control design } \\
\text { avoided? }\end{array}$ & $\begin{array}{c}\text { Did the } \\
\text { study avoid } \\
\text { inappropriate } \\
\text { exclusions? }\end{array}$ & $\begin{array}{l}\text { Could the } \\
\text { selection of } \\
\text { patients have } \\
\text { introduced bias? }\end{array}$ & $\begin{array}{l}\text { Is there } \\
\text { concern the } \\
\text { included } \\
\text { patients do } \\
\text { not match } \\
\text { the review } \\
\text { question? }\end{array}$ & $\begin{array}{l}\text { Were the index } \\
\text { test results } \\
\text { interpreted } \\
\text { without } \\
\text { knowledge of } \\
\text { the results of } \\
\text { the reference } \\
\text { standard? }\end{array}$ & $\begin{array}{l}\text { If a threshold } \\
\text { was used, } \\
\text { was it pre- } \\
\text { specified? }\end{array}$ & $\begin{array}{l}\text { Could the } \\
\text { conduct or } \\
\text { interpretation } \\
\text { of the index } \\
\text { test have } \\
\text { introduced } \\
\text { bias? }\end{array}$ & $\begin{array}{l}\text { Is there concern } \\
\text { that the index } \\
\text { test, its conduct, } \\
\text { or interpretation } \\
\text { differ from the } \\
\text { review question? }\end{array}$ & $\begin{array}{l}\text { Is the reference } \\
\text { standard likely } \\
\text { to correctly } \\
\text { classify the target } \\
\text { condition? }\end{array}$ & $\begin{array}{c}\text { Were the } \\
\text { reference } \\
\text { standard results } \\
\text { interpreted } \\
\text { without } \\
\text { knowledge of } \\
\text { the results of } \\
\text { the index test? }\end{array}$ & $\begin{array}{l}\text { Could the } \\
\text { reference } \\
\text { standard, its } \\
\text { conduct, or its, } \\
\text { interpretation } \\
\text { have introduced } \\
\text { bias? }\end{array}$ & $\begin{array}{l}\text { Is there } \\
\text { concern } \\
\text { the target } \\
\text { condition as } \\
\text { defined by } \\
\text { the reference } \\
\text { standard does } \\
\text { not match } \\
\text { the review } \\
\text { question? }\end{array}$ & $\begin{array}{l}\text { Was there an } \\
\text { appropriate } \\
\text { interval between } \\
\text { index tests } \\
\text { and reference } \\
\text { standard? }\end{array}$ & $\begin{array}{l}\text { Did all patients } \\
\text { receive a } \\
\text { reference } \\
\text { standard? }\end{array}$ & \begin{tabular}{l}
\multicolumn{1}{c}{ Did } \\
patients \\
receive \\
the same \\
reference \\
standard?
\end{tabular} & $\begin{array}{c}\text { Were all } \\
\text { patients } \\
\text { included in } \\
\text { the analysis? }\end{array}$ & $\begin{array}{c}\text { Could the } \\
\text { patient } \\
\text { flow have } \\
\text { introduced } \\
\text { bias? }\end{array}$ \\
\hline
\end{tabular}

\begin{tabular}{|c|c|c|c|c|c|c|c|c|c|c|c|c|c|c|c|c|c|c|}
\hline \multicolumn{19}{|l|}{ Calprotectin } \\
\hline Abdel Rahman et al. (24) & Unclear & Yes & Yes & Low & Low & Unclear & No & Low & Low & Yes & No & Low & Low & Yes & Yes & Yes & No & Low \\
\hline Abdel-Razik et al. (25) & Yes & Yes & Yes & Low & Low & Yes & No & Low & Low & Yes & No & Low & Low & Yes & Yes & Yes & No & Low \\
\hline Ali et al. (26) & Unclear & Unclear & Yes & Low & Low & Unclear & No & Low & Low & Yes & No & Low & Low & Yes & Yes & Yes & Yes & Low \\
\hline El-Baz et al. (27) & Unclear & No & Yes & High & Low & Unclear & No & Low & Low & Yes & No & Low & Low & Yes & Yes & Yes & Yes & Low \\
\hline Fernades et al. (9) & Yes & Yes & Yes & Low & Low & Yes & No & Low & Low & Yes & No & Low & Low & Yes & Yes & Yes & Yes & Low \\
\hline Gad et al. (28) & No & No & Yes & High & Low & Unclear & No & Low & Low & Yes & No & Low & Low & Yes & Yes & Yes & Yes & Low \\
\hline Heikl et al. (29) & No & No & Yes & High & Low & Unclear & No & Low & Low & Yes & No & Low & Low & Yes & Yes & Yes & Yes & Low \\
\hline Kassem et al. (30) & Yes & No & Yes & High & Low & Unclear & No & Low & Low & Yes & No & Low & Low & Yes & Yes & Yes & Yes & Low \\
\hline Makhlouf et al. (31) & Yes & Yes & Yes & Low & Low & Yes & No & Low & Low & Yes & No & Low & Low & Yes & Yes & Yes & Yes & Low \\
\hline Mohammed et al. (32) & No & No & Yes & High & Low & Unclear & No & Low & Low & Yes & No & Low & Low & Yes & Yes & Yes & Yes & Low \\
\hline Rizk et al. (14) & Yes & Yes & Yes & Low & Low & Yes & No & Low & Low & Yes & No & Low & Low & Yes & Yes & Yes & No & Low \\
\hline Weil et al. (33) & Yes & Yes & Yes & Low & Low & Yes & No & Low & Low & Yes & No & Low & Low & Yes & Yes & Yes & Yes & Low \\
\hline \multicolumn{19}{|l|}{ Lactoferrin } \\
\hline Abuelfadi et al. (34) & Unclear & No & Yes & High & Low & Unclear & No & Low & Low & Yes & No & Low & Low & Yes & Yes & Yes & Yes & Low \\
\hline Al Sawaf et al. (35) & Yes & Yes & Yes & Low & Low & Yes & No & Low & Low & Yes & Unclear & Low & Low & Yes & Yes & Yes & Yes & Low \\
\hline Ali et al. (36) & Unclear & Unclear & Yes & Low & Low & No & No & Low & Low & Yes & No & Low & Low & Yes & Yes & Yes & Yes & Low \\
\hline Chen et al. (37) & Yes & Yes & Yes & Low & Low & Yes & No & Low & Low & Yes & Yes & Low & Low & Yes & Yes & Yes & Yes & Low \\
\hline El-Baz et al. (27) & Unclear & No & Yes & High & Low & No & No & Low & Low & Yes & Yes & Low & Low & Yes & Yes & Yes & Yes & Low \\
\hline Kumar et al. (38) & Yes & Yes & Unclear & Low & Low & Yes & No & Low & Low & Yes & No & Low & Low & Yes & Yes & Yes & Yes & Low \\
\hline Lee et al. (39) & Yes & Yes & Yes & Low & Low & Yes & No & Low & Low & Yes & Yes & Low & Low & Yes & Yes & Yes & No & Low \\
\hline Liang et al. (40) & Unclear & Yes & Unclear & High & Low & Unclear & No & Low & Low & Yes & Unclear & Low & Low & Yes & Yes & Yes & Yes & Low \\
\hline Makhlouf et al. (31) & Yes & Yes & Yes & Low & Low & Yes & No & Low & Low & Yes & Yes & Low & Low & Yes & Yes & Yes & Yes & Low \\
\hline Mohammad et al. (41) & Yes & Yes & Unclear & Low & Low & Yes & No & Low & Low & Yes & No & Low & Low & Yes & Yes & Yes & Yes & Low \\
\hline Parsi et al. (7) & Yes & Yes & Yes & Low & Low & Unclear & No & Low & Low & Yes & Unclear & Low & Low & Yes & Yes & Yes & Yes & Low \\
\hline Salman et al. (42) & Yes & Yes & Yes & Low & Low & Yes & No & Low & Low & Yes & No & Low & Low & Yes & Yes & Yes & Yes & Low \\
\hline
\end{tabular}

QUADAS, quality assessment of diagnostic accuracy studies; SBP, spontaneous bacterial peritonitis. 